\title{
Difference in Membrane Repair Capacity Between Cancer Cell Lines and a Normal Cell Line
}

\author{
Stine Krog Frandsen ${ }^{1}$ Anna K. McNeil ${ }^{2}$ Ivana Novak $^{3}$ - Paul L. McNeil ${ }^{2}$. \\ Julie Gehl ${ }^{1}$ (B)
}

Received: 2 March 2016/Accepted: 6 June 2016/Published online: 16 June 2016

(c) The Author(s) 2016. This article is published with open access at Springerlink.com

\begin{abstract}
Electroporation-based treatments and other therapies that permeabilize the plasma membrane have been shown to be more devastating to malignant cells than to normal cells. In this study, we asked if a difference in repair capacity could explain this observed difference in sensitivity. Membrane repair was investigated by disrupting the plasma membrane using laser followed by monitoring fluorescent dye entry over time in seven cancer cell lines, an immortalized cell line, and a normal primary cell line. The kinetics of repair in living cells can be directly recorded using this technique, providing a sensitive index of repair capacity. The normal primary cell line of all tested cell lines exhibited the slowest rate of dye entry after laser disruption and lowest level of dye uptake. Significantly, more rapid dye uptake and a higher total level of dye uptake occurred in six of the seven tested cancer cell lines $(p<0.05)$ as well as the immortalized cell line $(p<0.001)$. This difference in sensitivity was also observed when a viability assay was performed one day after plasma membrane permeabilization by electroporation. Viability in the primary normal cell line $(98 \%$ viable cells) was higher than in the three tested cancer cell lines (81-88\% viable cells). These data suggest more effective membrane repair in normal, primary cells and supplement
\end{abstract}

Julie Gehl

karen.julie.gehl@regionh.dk

1 Center for Experimental Drug and Gene Electrotransfer, Department of Oncology, Herlev and Gentofte Hospital, University of Copenhagen, Herlev, Denmark

2 Department of Cellular Biology and Anatomy, Georgia Regents University, Augusta, GA, USA

3 Section for Cell Biology and Physiology, Department of Biology, University of Copenhagen, Copenhagen, Denmark previous explanations why electroporation-based therapies and other therapies permeabilizing the plasma membrane are more effective on malignant cells compared to normal cells in cancer treatment.

Keywords Membrane repair - Electroporation - Cancer . Normal · In vitro

\section{Introduction}

Electroporation is increasingly being used in cancer treatment strategies (Kee et al. 2011). It is a method where application of short, high-voltage pulses induces transient permeabilization of the cell membrane and thus allows the passage of ions and molecules into and out of the cell (Orlowski and Mir 1993; Gehl 2003; Frandsen et al. 2012; Vasquez et al. 2015). The membrane reseals within a few minutes depending on the parameters used (reversible electroporation) and if the electric field is high enough, the membrane does not reseal and results in irreversible electroporation (Rols and Teissie 1990). Clinically, in anticancer treatments, this method is used as irreversible electroporation (without added drugs) (Martin et al. 2015) and as reversible electroporation in combination with chemotherapeutic drugs (electrochemotherapy) (Belehradek et al. 1993; Marty et al. 2006; Matthiessen et al. 2012), calcium (calcium electroporation) (ClinicalTrials.gov IDNCT01941901), and DNA drugs (gene electrotransfer) (Mir et al. 1999; Daud et al. 2008; Spanggaard et al. 2013). Electrochemotherapy is standardly used for the treatment of cutaneous metastases, and clinical trials for the treatment of internal tumors are ongoing using new electrode designs (Edhemovic et al. 2011). Interestingly, it has been a consistent clinical observation that normal tissue is much 
less affected than malignant tissues when treating with electrochemotherapy (Fig. 1; Gehl 2005) as well as with irreversible electroporation (Neal et al. 2011). Recently, similar results for calcium electroporation were shown in a $3 \mathrm{D}$ in vitro model where normal cell spheroids were much less affected by calcium electroporation than cancer cell spheroids (Frandsen et al. 2015). It has also been shown in vitro that sonoporation, a method where application of low-power ultrasound permeabilizes the cell membrane, causes different effects in normal and malignant cells (Lejbkowicz et al. 1993; Lejbkowicz and Salzberg 1997).

These differences in sensitivity between normal and cancer cells when permeabilizing the plasma membrane, independent of the method used, could indicate a difference in susceptibility of cells to permeabilization treatments or the capacity to rapidly reseal after permeabilization. We aimed to investigate if differences in membrane repair in a number of cancer cell lines, an immortalized cell line, and a normal primary cell line could be part of the explanation for the observed difference in sensitivity between normal and cancer cells for treatments using permeabilization methods. The extent of permeabilization after electroporation is known to depend on different factors including membrane composition (Levine and Vernier 2012), cell size (Teissie and Rols 1993), cell shape (Pucihar et al. 2006), and cell density (Pucihar et al. 2007) in the suspension. To our knowledge the observed difference in sensitivity between malignant and normal cells has been an empirical finding, for which mechanisms still need to be elucidated. We therefore decided to investigate membrane repair by disrupting the plasma membrane using laser technology, since holes created by laser, in contrast to permeabilization after electroporation, are equal in size independent of cell type (Bansal et al. 2003; Howard et al. 2011a, b), allowing us to investigate membrane repair separately from the level of membrane poration. We show that when using a laser to disrupt the plasma membrane in the presence of a fluorescent dye, the rate and extent of dye entry in the normal dermal fibroblast was the lowest in all tested cell lines and significantly reduced compared to that in six of the seven tumor-derived cell lines as well as the immortalized cell line. Thus, the normal fibroblast cell line appeared to have a faster membrane repair. These empiric observations could help explain the differential sensitivity to electrochemotherapy and calcium electroporation between normal and malignant cells.

\section{Materials and Methods}

This was a collaborative study where the laser experiments were performed in Georgia, USA and the electroporation experiments were performed in Copenhagen, Denmark.

\section{Cell Culture}

Nine different human cell lines were used in this study; seven cancer cell lines, an immortalized normal cell line, and one primary normal cell line (Table 1). (1) H69, a small cell lung carcinoma kindly provided by the Department of Radiation Biology, Copenhagen University Hospital, Denmark (Gjetting et al. 2010), (2) HT29, a colorectal adenocarcinoma (ATCC \#HTB-38), (3) MKN28, a gastric adenocarcinoma and (4) MKN-45, a gastric carcinoma kindly provided by Dr. Katsuya Miyake, Kagawa University, Japan (Fukui et al. 2003), and (5) PC3$\mathrm{M}$, a prostate cancer derived from a bone metastasis (ATCC \#CRL-1435). These cell lines were all grown in RPMI-1640 culture medium (Gibco, Invitrogen). (6) MRC5, an immortalized lung fibroblast (ATCC \#CCL171) was grown in EMEM culture medium (Gibco, Invitrogen). (7) MDA-MB-231, a breast adenocarcinoma (ATCC \#HTB-26), (8) SW780, a bladder transitional cell
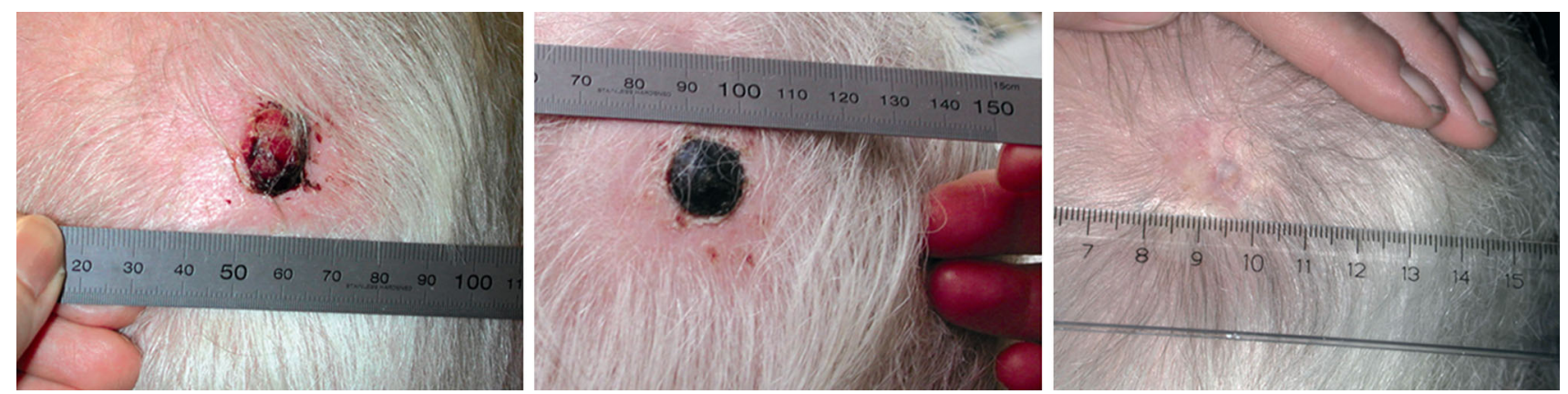

Fig. 1 Malignant melanoma treated with electrochemotherapy. Pictures of a malignant melanoma patient before (left), 1 month (middle), and 6 months (right) after treatment with electrochemotherapy using bleomycin showing complete remission of the tumor 6 months after treatment. Note the needle marks seen in surrounding normal tissue 1 month after treatment showing that normal tissue is much less affected by electrochemotherapy then the cancer tissue (Gehl 2005) 
Table 1 Cell lines used in this study

\begin{tabular}{|c|c|c|c|}
\hline Cell line & Phenotype characteristics & Source & References \\
\hline H69 & Human small cell lung carcinoma & $\begin{array}{l}\text { Kindly provided by the Department of Radiation } \\
\text { Biology, Copenhagen University Hospital, Denmark }\end{array}$ & Gjetting et al. (2010) \\
\hline HDF-n & $\begin{array}{l}\text { Human primary normal human dermal } \\
\text { fibroblasts (not immortalized) }\end{array}$ & $\begin{array}{l}\text { Kindly provided by Dr. Marie-Pierre Rols, Institute of } \\
\text { Pharmacology and Structural Biology, IPBS, } \\
\text { Toulouse, France }\end{array}$ & Frandsen et al. (2015) \\
\hline HT29 & Human colorectal adenocarcinoma & ATCC \#HTB-38 & $\begin{array}{l}\text { http://atcc.org/ } \\
\text { Products/All/HTB- } \\
\text { 38.aspx }\end{array}$ \\
\hline MDA-MB-231 & Human breast adenocarcinoma & ATCC \#HTB-26 & $\begin{array}{l}\text { http://atcc.org/ } \\
\text { Products/All/HTB- } \\
\text { 26.aspx }\end{array}$ \\
\hline MKN-28 & Human gastric adenocarcinoma & $\begin{array}{l}\text { Kindly provided by Dr. Katsuya Miyake, Kagawa } \\
\text { University, Japan }\end{array}$ & Fukui et al. (2003) \\
\hline $\mathrm{MKN}-45$ & Human gastric carcinoma & $\begin{array}{l}\text { Kindly provided by Dr. Katsuya Miyake, Kagawa } \\
\text { University, Japan }\end{array}$ & Fukui et al. (2003) \\
\hline MRC5 & Immortalized human lung fibroblast & ATCC \#CCL-171 & $\begin{array}{l}\text { http://atcc.org/ } \\
\text { Products/All/CCL- } \\
\text { 171.aspx }\end{array}$ \\
\hline PC3-M & $\begin{array}{l}\text { Human prostate cancer derived from a } \\
\text { bone metastasis }\end{array}$ & ATCC \#CRL-1435 & $\begin{array}{l}\text { http://atcc.org/ } \\
\text { Products/All/CRL- } \\
\text { 1435.aspx }\end{array}$ \\
\hline SW780 & $\begin{array}{l}\text { Human bladder transitional cell } \\
\text { carcinoma }\end{array}$ & $\begin{array}{l}\text { Kindly provided by Dr. Lars Dyrskjøt Andersen, } \\
\text { Department of Molecular Medicine, Aarhus University } \\
\text { Hospital, Skejby, Denmark }\end{array}$ & Herbsleb et al. (2008) \\
\hline
\end{tabular}

The name, phenotype characteristics, source, and references of the nine different cell lines used in this study are presented in the table

carcinoma kindly provided by Dr. Lars Dyrskjøt Andersen, Department of Molecular Medicine, Aarhus University Hospital, Skejby, Denmark (Herbsleb et al. 2008), and (9) primary normal human dermal fibroblasts HDF-n kindly provided by Dr. Marie-Pierre Rols, Institute of Pharmacology and Structural Biology, IPBS, Toulouse, France (Frandsen et al. 2015) were grown in DMEM culture medium (Gibco, Invitrogen). All cells grew with $10 \%$ fetal calf serum (Gibco, Invitrogen), $100 \mathrm{U} / \mathrm{ml}$ penicillin, and $100 \mu \mathrm{g} / \mathrm{ml}$ streptomycin and were maintained at $37{ }^{\circ} \mathrm{C}$ and $5 \% \mathrm{CO}_{2}$. All cells were tested negative for mycoplasma using MycoAlert mycoplasma detection kit (Lonza).

\section{Membrane Repair}

A well-characterized assay (Bansal et al. 2003) was used to assess membrane repair. Membrane repair is initiated by creating a lesion of a well-defined size and shape (software selectable) in cells immersed in the dye, FM1-43. Previous studies have demonstrated that lesions of a defined size can reproducibly be made using this technique (Bansal et al. 2003; Howard et al. 2011a, b). FM1-43 is non-fluorescent in water, but highly fluorescent in a non-polar environment, such as cell membranes. It is capable moreover of rapidly partitioning into and out of lipid bilayers, but cannot cross them. In the absence of a lesion, therefore, only the surface lipid bilayer, the plasma membrane, is labeled, as well as over time (hours) endosomal pathway membranes. Over the time course of the typical repair experiment, this endocytotic accumulation of fluorescence is however insignificant (Bansal et al. 2003; Howard et al. 2011a; b). When a membrane lesion is created with the laser, dye in medium can freely enter the cell, where it then partitions into internal membrane compartments, adding internal fluorescence signal. Accumulation of this signal continues until repair is completed. Continuing accumulation of internal fluorescence, recorded by measuring integrated cellular fluorescence signal over time, therefore provides an accurate record of the duration of lesion opening, and the cessation of dye accumulation marks repair completion. Briefly, cultured cells were wounded in PBS, with or without $1.2 \mathrm{mM} \mathrm{Ca}^{2+}$, containing $2.5 \mu \mathrm{M}$ FM $1-43$ (Invitrogen). Laser injury was produced using a 2-photon laser scanning confocal microscope (LSM 780 Multiphoton Microscope, Zeiss) coupled to a Vision $\mathrm{S}$ tunable laser (Coherent) at $100 \%$ power (one laser iteration and a 15 pixels diameter circle bleach area placed over the membrane edge), creating $1.66 \mu \mathrm{m}$ diameter plasma membrane disruptions. Fluorescence intensity over time was quantified using ZEN 2012, Zeiss software. 


\section{Viability After Electroporation (With or Without Added Calcium)}

The primary normal cell line (HDF-n) and three cancer cell lines (HT29, MDA-MB231, and SW780) were tested for viability after electroporation. These cell lines were chosen to compare the normal cell line with a few of the cancer cells lines that had shown a clear difference in membrane repair.

After harvesting, cells were washed in HEPES buffer (10 mM HEPES, $250 \mathrm{mM}$ sucrose, and $1 \mathrm{mM} \mathrm{MgCl}_{2}$ in sterile water) and diluted to $5.5 \times 10^{6}$ cells $/ \mathrm{ml}$ HEPES buffer. In $4 \mathrm{~mm}$ cuvettes with aluminum electrodes (Molecular BioProducts, Inc.) $300 \mu \mathrm{l}$ cooled cells $\left(8^{\circ} \mathrm{C}\right)$ were electroporated by delivering 8 pulses of $100 \mu \mathrm{s}$, $1.2 \mathrm{kV} / \mathrm{cm}$, and $1 \mathrm{~Hz}$ using a BTX T820 square wave electroporator. After $20 \mathrm{~min}$ incubation at $37{ }^{\circ} \mathrm{C}$ and $5 \%$ $\mathrm{CO}_{2}$ cells were diluted in culture medium to $3.1 \times 10^{5}$ cells $/ \mathrm{ml}$ and seeded in 96 -well plates $(100 \mu \mathrm{l} /$ well). One day after treatment viability was measured by MTS assay (Malich et al. 1997) using Multiskan-Ascent ELISA reader (Thermo Labsystems).

\section{Permeabilization After Electroporation}

The primary normal cell line (HDF-n) and the bladder cancer cell line (SW780) were tested for degree of permeabilization after electroporation. These cell lines were chosen since they showed a significant difference in viability after electroporation.

Cells were plated in Willco wells (30.000 cells in $2 \mathrm{ml}$ medium; WillCo Wells BV, The Netherlands) one day prior to experiments. Cells were washed in $1 \mathrm{ml} \mathrm{Krebs-}$ Ringer buffer ( $25 \mathrm{mM}$ Na-gluconate, $120 \mathrm{mM} \mathrm{NaCl}$, $1 \mathrm{mM} \mathrm{MgCl} 2 \cdot 6 \mathrm{H}_{2} \mathrm{O}, 0.4 \mathrm{mM} \mathrm{KH}{ }_{2} \mathrm{PO}_{4}, 1.6 \mathrm{mM} \mathrm{K}_{2} \mathrm{HPO}_{4}$. $3 \mathrm{H}_{2} \mathrm{O}, 1.5 \mathrm{mM} \mathrm{CaCl} 2 \cdot 2 \mathrm{H}_{2} \mathrm{O}, 10 \mathrm{mM}$ glucose $\cdot \mathrm{H}_{2} \mathrm{O}$ in MiliQ water) before adding $400 \mu \mathrm{l}$ Krebs-Ringer buffer containing $1 \mu \mathrm{M}$ YO-PRO-1 (Invitrogen) and incubated at $37{ }^{\circ} \mathrm{C}$ and $0 \% \mathrm{CO}_{2}$ for $30 \mathrm{~min}$. YO-PRO-1 is a fluorescent dye that binds to nucleic acids after entering cells when plasma cell membranes are permeabilized (e.g., electroporation, during apoptosis, induction of pore channels). Cells were treated with electroporation (8 pulses of $1.2 \mathrm{kV} /$ $\mathrm{cm}, 100 \mu \mathrm{s}$, and $1 \mathrm{~Hz}$ ) using a Cliniporator (IGEA, Italy) and a custom-made contact copper electrode with $8 \mathrm{~mm}$ between the electrodes (Fig. 2). Electroporation parameters were optimized for both cell lines for high permeabilization and high viability, and the same parameters were used for both cell lines. Pictures were taken before treatment and 3 min after treatment using a Leica DMI6000B microscope connected to a Leica DFC450C camera. Mean fluorescence intensity in cells was calculated using Image $\mathbf{J}$ software (NIH, Bethesda, USA).

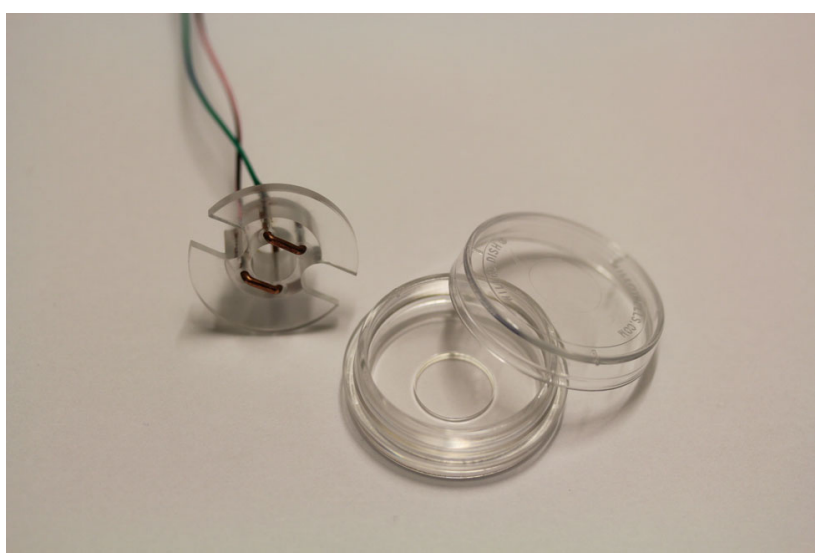

Fig. 2 Custom-made contact copper electrode. Picture of the electrode used for the experiment testing permeabilization after electroporation. The electrode is made to fit in a Willco Well

\section{Graphics and Statistics}

All artwork was created using GraphPad Prism 6. Statistical analyses were performed using SAS software (version 9.2). Difference in fluorescence intensity in the different cell lines was evaluated as repeated measurements, validated and analyzed with an exponential decrease model with Bonferroni correction. "Cell line," "Time," and "n" were used as factors and baseline level of fluorescence intensity were used as covariant. Difference in viability after electroporation between different cell lines and difference in permeabilization after electroporation between HDF-n and SW780 cell lines were assessed using one-way analysis of variance (ANOVA) with Bonferroni correction. Difference in viability after electroporation with addition of calcium between HDF-n and HT29 cell lines was assessed using two-way ANOVA with Bonferroni correction.

\section{Results and Discussion}

To compare membrane repair in different cancer cell lines, an immortalized cell line, and a normal primary cell line, we measured the rate and extent of fluorescent dye entry after rupture of the plasma membrane using a laser (Figs. 3, 4). Nine different cell lines (seven cancer cell lines, an immortalized cell line, and a normal primary cell line) were tested to investigate membrane repair in a variety of different tumor types. The method used for testing membrane repair is a well-known method where a disruption in the plasma membrane is created using a laser (Bansal et al. 2003). This creates $1.66 \mu \mathrm{m}$ diameter plasma membrane disruptions, and the size of the disruption does not depend on the cell type. The fluorescent dye enters 


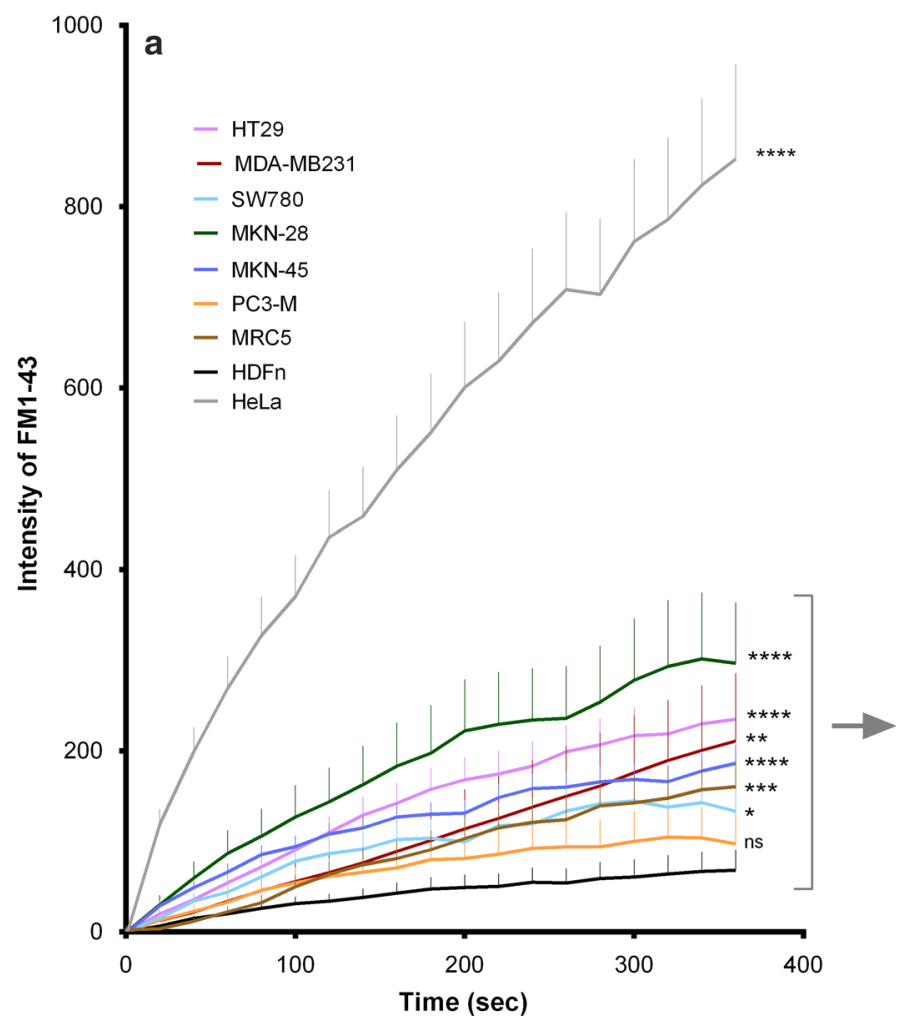

Fig. 3 Membrane repair capability. Intensity of FM1-43 in nine different cell lines (seven cancer cell lines, an immortalized cell line, and a normal primary cell line) after disrupting the plasma membrane using laser. a All tested cell lines including the immortalized cell line

through the membrane disruption, but further entry is hindered when plasma membrane repair is initiated. Prior dye entry by endocytosis into cytoplasm is ignored (subtraction of signal during analysis) and entry during the repair measurement is insignificant (second time scale). The rate and extent of dye entry in the normal primary cells was the lowest of all tested cell lines and significantly reduced compared to all the tumor-derived lines $(p<0.05)$ with one exception being the PC3-M cell line derived from a bone metastasis of a prostate cancer $(p=0.29)$ (Fig. 3). In five of seven cancer-derived cell lines, dye entry continued throughout the time course of the experiment (360 s). Thus, membrane repair either failed or was less effective in these tumor-derived cell lines indicating a less efficient membrane repair system. Especially HeLa cells have a much less effective membrane repair than all the other tested cell lines (Figs. 3a, 4). The immortalized normal cell line (MRC5, a human lung cell line) showed a slightly higher dye entry than the primary normal cell line (Fig. 3a). However, dye entry in the immortalized cell line was still in the lower half of the tested cell lines. Possible changes in membrane composition and/or membrane function when immortalizing the cell line may explain why this cell line does not exhibit dye entry equivalent to the

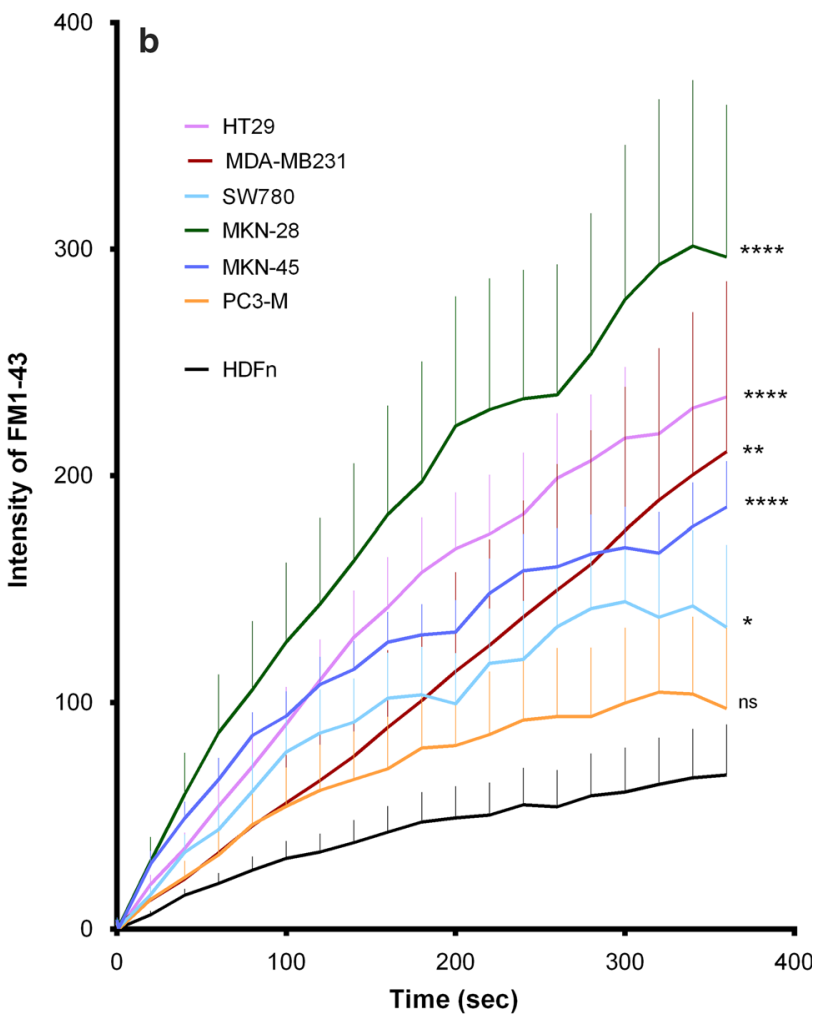

and the HeLa cell line. b Six of the tested cancer cell lines and the normal primary cell line, (note the changed $y$-axis). Data are shown as mean + SEM, $n=7-22$, significance at $360 \mathrm{~s}$ shown, $* p<0.05$, $*^{*} p<0.01, * * * p<0.001, * * * * p<0.0001, n s$ not significant

primary normal cells. However, further investigations are needed to clarify if normal and immortalized cell lines in general show difference in membrane repair.

As previously described, permeabilization induced by electroporation depends on the cell type (membrane composition, cell size, and cell shape) (Teissie and Rols 1993; Pucihar et al. 2006; Levine and Vernier 2012). Differences in viability after electroporation have previously been explained by differences in permeabilization due to the different cell types. However, this study suggests that differences in membrane repair after permeabilization might also affect the viability. Electroporation induces permeabilization of the plasma membrane with more but smaller pores (Gehl 2003; Levine and Vernier 2012) compared with laser disruption, and this might lead to different repair mechanisms in the two cases.

To test if this difference in membrane repair has an effect on viability when permeabilizing the plasma membrane by electroporation, we electroporated four of the used cell lines (three cancer cell lines and the normal primary cell line, previously used in another study (Frandsen et al. 2015)) and measured viability one day after treatment (Fig. 5). The normal primary cells showed the highest viability $(98 \%)$ after electroporation, significantly higher 
Fig. 4 Images of FM1-43 intensity. Representative images of three cancer cells (HeLa, HT29, SW780) and a normal primary cell (HDF-n) showing fluorescence before and 40, 120, and $200 \mathrm{~s}$ after disrupting the plasma membrane using a laser in the presence of FM1-43.

Scale bar in bottom right corner is $10 \mu \mathrm{m}$
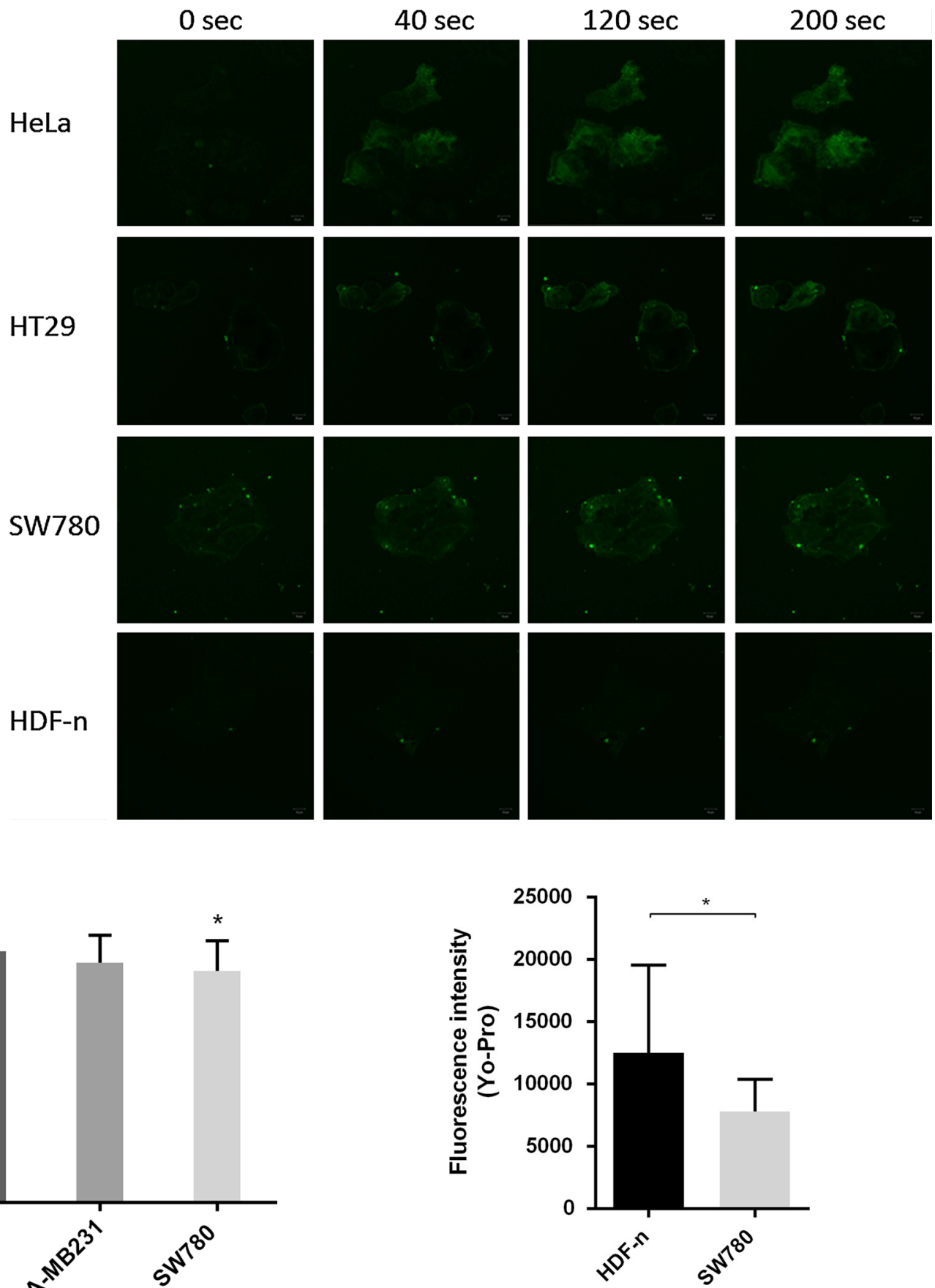

Fig. 6 Permeabilization after electroporation. A normal primary cell line (HDF-n) and a bladder cancer cell line (SW780) electroporated in the presence of the non-permeant dye Yo-Pro-1. Fluorescence intensity was measured $3 \mathrm{~min}$ after electroporation. Data are shown as mean $+\mathrm{SD} n=4, * p<0.05$

permeabilization after electroporation in the two cell lines in the presence of the fluorescent dye YO-PRO-1, we showed that uptake of the dye was significantly higher in the normal cell line than in the cancer cell line. This indicates higher degree of permeabilization of the normal cell line after electroporation, when using the same 
electroporation parameters for both cell lines (Fig. 6). In other words, the normal cell line does get permeabilized by electroporation (even to a higher extent than the malignant cell line tested), but repairs faster when a direct comparison is made as the laser holes are comparable across cell lines. Thus, normal cells seem to recover more effectively, likely explaining the higher survival rate (Fig. 5). Survival after electroporation is determined by a number of factors, including the degree of membrane permeabilization, but also energy level and other intracellular factors. As seen in Fig. 3, there is a significant difference in membrane repair between normal and malignant cell lines, which may in part explain the difference in survival after electroporation. However, a more pronounced difference of late membrane repair would ensue when drugs (such as bleomycin) were added.

The results of this study indicate that there is a reduced ability of membrane repair in cancer cells compared with the normal cells. This might contribute to the difference in survival and effectivity of treatment on normal and cancer cells and tissues when using permeabilization methods as reported earlier (Lejbkowicz et al. 1993; Lejbkowicz and Salzberg 1997; Marty et al. 2006; Neal et al. 2011; Frandsen et al. 2015; Landstrom et al. 2015). Further investigations are needed. A possible difference in membrane repair might be caused by changes in the repair mechanisms and/or membrane composition in cancer cells. Membrane repair is a very complex system including several mechanisms and involving numerous proteins (Boucher and Mandato 2015). Many different $\mathrm{Ca}^{2+}$-sensors are involved in membrane repair including calpains, annexins, and $\mathrm{S} 100$ proteins. These sensors are activated by the high $\mathrm{Ca}^{2+}$ entry at the site of the injured membrane and initiate the membrane repair process (McNeil et al. 2006; Jaiswal et al. 2014; Boucher and Mandato 2015). Changes in the expression of these proteins might change the membrane repair mechanisms. Interestingly, expression of S100 and annexin proteins has been shown to be changed in many different cancer types (Bresnick et al. 2015; Wei et al. 2015). Thus, it would be relevant to make further investigation on the expression of these proteins in the 9 cell lines used in this study in order to test a possible correlation with the shown membrane repair results. The changed composition of lipids in the plasma membrane has also been shown in cancer cells, such as more negative charge, elevated levels of cholesterol, and the presence of certain lipids in the outer and inner leaflet (Zwaal et al. 2005; Schweizer 2009). A changed membrane composition might also affect membrane repair.

When treating cutaneous metastases with electrochemotherapy in the clinic, the surrounding normal tissue is less affected than the tumor tissue (Fig. 1) and it has been proposed to be due to the increased effect of chemotherapeutic drugs on fast-dividing cells as well as an increased conductivity in tumor tissue increasing the permeabilization (Mir et al. 1996; Laufer et al. 2010). The present study may supplement the previous explanations on the clear difference in sensitivity of cancer and normal cells treated with electrochemotherapy (Marty et al. 2006), as well as after calcium electroporation (Frandsen et al. 2015), other electroporation-based therapies (Neal et al. 2011), and other therapies causing membrane permeabilization such as sonoporation-based therapies (Lejbkowicz et al. 1993; Lejbkowicz and Salzberg 1997) as well as ionizing radiation (Hannig et al. 2000).

\section{Conclusion}

In conclusion, membrane repair was less effective in six of the seven tested cancer cell lines and the immortalized cell line compared with the normal primary fibroblasts. This result could be part of the explanation why electroporationbased therapies and other therapies permeabilizing the plasma membrane are more effective in inducing cell death of malignant than normal cells. However, further investigations are needed to substantiate these results and investigate in more detail about membrane repair mechanisms and membrane composition in the different cell lines.

Acknowledgments The authors thank Marianne Fregil for providing excellent technical assistance.

Funding The study was funded by the University of Copenhagen (S.K. Frandsen), the Danish Council for Independent Research, Natural Sciences no. 4002-00162 and FP7 Marie Curie ITN "IonTraC" no. 289648 (I. Novak), The Danish Cancer Society R110-A6996 (J. Gehl).

\section{Compliance With Ethical Standards}

Conflict of Interest A patent has been submitted and licensed- PCT/ DK2012/050496 (co-inventors: S.K. Frandsen and J. Gehl).

Open Access This article is distributed under the terms of the Creative Commons Attribution 4.0 International License (http://crea tivecommons.org/licenses/by/4.0/), which permits unrestricted use, distribution, and reproduction in any medium, provided you give appropriate credit to the original author(s) and the source, provide a link to the Creative Commons license, and indicate if changes were made.

\section{References}

Bansal D, Miyake K, Vogel SS, Groh S, Chen CC, Williamson R, McNeil PL, Campbell KP (2003) Defective membrane repair in dysferlin-deficient muscular dystrophy. Nature 423:168-172

Belehradek M, Domenge C, Luboinski B, Orlowski S, Belehradek J Jr, Mir LM (1993) Electrochemotherapy, a new antitumor treatment. First Clinical Phase I-II trial. Cancer 72:3694-3700 
Boucher E, Mandato CA (2015) Plasma membrane and cytoskeleton dynamics during single-cell wound healing. Biochim Biophys Acta 1853:2649-2661

Bresnick AR, Weber DJ, Zimmer DB (2015) S100 proteins in cancer. Nat Rev Cancer 15:96-109

Daud AI, DeConti RC, Andrews S et al (2008) Phase I trial of interleukin-12 plasmid electroporation in patients with metastatic melanoma. J Clin Oncol 26:5896-5903

Edhemovic I, Gadzijev EM, Brecelj E et al (2011) Electrochemotherapy: a new technological approach in treatment of metastases in the liver. Technol Cancer Res Treat 10:475-485

Frandsen SK, Gissel H, Hojman P, Tramm T, Eriksen J, Gehl J (2012) Direct therapeutic applications of calcium electroporation to effectively induce tumor necrosis. Cancer Res 72:1336-1341

Frandsen SK, Gibot L, Madi M, Gehl J, Rols MP (2015) Calcium electroporation: evidence for Differential effects in normal and malignant cell lines, evaluated in a 3D spheroid model. PLoS One 10:e0144028. doi:10.1371/journal.pone.0144028

Fukui T, Matsui K, Kato H, Takao H, Sugiyama Y, Kunieda K, Saji S (2003) Significance of apoptosis induced by tumor necrosis factor-alpha and/or interferon-gamma against human gastric cancer cell lines and the role of the p53 gene. Surg Today 33:847-853. doi:10.1007/s00595-003-2620-5

Gehl J (2003) Electroporation: theory and methods, perspectives for drug delivery, gene therapy and research. Acta Physiol Scand 177:437-447

Gehl J (2005) Investigational treatment of cancer using electrochemotherapy, electrochemoimmunotherapy and electro-gene transfer. Ugeskr Laeger 167:3156-3159

Gjetting T, Arildsen NS, Christensen CL, Poulsen TT, Roth JA, Handlos VN, Poulsen HS (2010) In vitro and in vivo effects of polyethylene glycol (PEG)-modified lipid in DOTAP/cholesterol-mediated gene transfection. Int J Nanomed 5:371-383

Hannig J, Zhang D, Canaday DJ, Beckett MA, Astumian RD, Weichselbaum RR, Lee RC (2000) Surfactant sealing of membranes permeabilized by ionizing radiation. Radiat Res 154:171-177

Herbsleb M, Birkenkamp-Demtroder K, Thykjaer T, Wiuf C, Hein AM, Orntoft TF, Dyrskjot L (2008) Increased cell motility and invasion upon knockdown of lipolysis stimulated lipoprotein receptor (LSR) in SW780 bladder cancer cells. BMC Med Genomics 1:31

Howard AC, McNeil AK, McNeil PL (2011a) Promotion of plasma membrane repair by vitamin E. Nat Commun 2:597. doi:10. 1038/ncomms 1594

Howard AC, McNeil AK, Xiong F, Xiong WC, McNeil PL (2011b) A novel cellular defect in diabetes: membrane repair failure. Diabetes 60:3034-3043. doi:10.2337/db11-0851

Jaiswal JK, Lauritzen SP, Scheffer L, Sakaguchi M, Bunkenborg J, Simon SM, Kallunki T, Jaattela M, Nylandsted J (2014) S100A11 is required for efficient plasma membrane repair and survival of invasive cancer cells. Nat Commun 5:3795

Kee ST, Gehl J, Lee EW (2011) Clinical aspects of electroporation. Springer, New York

Landstrom F, Ivarsson M, von Sydow AK, Magnuson A, von Beckerath M, Moller C (2015) Electrochemotherapy-evidence for cell-type selectivity in vitro. Anticancer Res 35:5813-5820

Laufer S, Ivorra A, Reuter VE, Rubinsky B, Solomon SB (2010) Electrical impedance characterization of normal and cancerous human hepatic tissue. Physiol Meas 31:995-1009. doi:10.1088/ 0967-3334/31/7/009

Lejbkowicz F, Salzberg S (1997) Distinct sensitivity of normal and malignant cells to ultrasound in vitro. Environ Health Perspect 105(Suppl 6): 1575-1578

Lejbkowicz F, Zwiran M, Salzberg S (1993) The response of normal and malignant cells to ultrasound in vitro. Ultrasound Med Biol $19: 75-82$
Levine ZA, Vernier PT (2012) Calcium and phosphatidylserine inhibit lipid electropore formation and reduce pore lifetime. J Membr Biol 245:599-610. doi:10.1007/s00232-012-9471-1

Malich G, Markovic B, Winder C (1997) The sensitivity and specificity of the MTS tetrazolium assay for detecting the in vitro cytotoxicity of 20 chemicals using human cell lines. Toxicology 124:179-192

Martin RC 2nd, Kwon D, Chalikonda S, Sellers M, Kotz E, Scoggins C, McMasters KM, Watkins K (2015) Treatment of 200 locally advanced (stage III) pancreatic adenocarcinoma patients with irreversible electroporation: safety and efficacy. Ann Surg 262:486-494. doi:10.1097/SLA.0000000000001441

Marty M, Sersa G, Garbay JR et al (2006) Electrochemotherapy-An easy, highly effective and safe treatment of cutaneous and subcutaneous metastases: Results of ESOPE (European Standard Operating Procedures of Electrochemotherapy) study. Eur J Cancer Suppl 4:3-13

Matthiessen LW, Johannesen HH, Hendel HW, Moss T, Kamby C, Gehl J (2012) Electrochemotherapy for large cutaneous recurrence of breast cancer: A. Acta Oncol 51:713-721

McNeil AK, Rescher U, Gerke V, McNeil PL (2006) Requirement for annexin A1 in plasma membrane repair. J Biol Chem 281:35202-35207

Mir LM, Tounekti O, Orlowski S (1996) Bleomycin: revival of an old drug. Gen Pharmacol 27:745-748

Mir LM, Bureau MF, Gehl J, Rangara R, Rouy D, Caillaud JM, Delaere P, Branellec D, Schwartz B, Scherman D (1999) Highefficiency gene transfer into skeletal muscle mediated by electric pulses. Proc Natl Acad Sci USA 96:4262-4267

Neal RE, Rossmeisl JH Jr, Garcia PA, Lanz OI, Henao-Guerrero N, Davalos RV (2011) Successful treatment of a large soft tissue sarcoma with irreversible electroporation. J Clin Oncol 29:e372e377

Orlowski S, Mir LM (1993) Cell electropermeabilization: a new tool for biochemical and pharmacological studies. Biochim Biophys Acta 1154:51-63

Pucihar G, Kotnik T, Valic B, Miklavcic D (2006) Numerical determination of transmembrane voltage induced on irregularly shaped cells. Ann Biomed Eng 34:642-652. doi:10.1007/ s10439-005-9076-2

Pucihar G, Kotnik T, Teissie J, Miklavcic D (2007) Electropermeabilization of dense cell suspensions. Eur Biophys J 36:173-185. doi:10.1007/s00249-006-0115-1

Rols MP, Teissie J (1990) Electropermeabilization of mammalian cells. Quantitative analysis of the phenomenon. Biophys $\mathbf{J}$ 58:1089-1098. doi:10.1016/S0006-3495(90)82451-6

Schweizer F (2009) Cationic amphiphilic peptides with cancerselective toxicity. Eur J Pharmacol 625:190-194. doi:10.1016/j. ejphar.2009.08.043

Spanggaard I, Snoj M, Cavalcanti A et al (2013) Gene electrotransfer of plasmid antiangiogenic metargidin peptide (AMEP) in disseminated melanoma: safety and efficacy results of a phase I first-in-man study. Hum Gene Ther Clin Dev 24:99-107. doi:10.1089/humc.2012.240

Teissie J, Rols MP (1993) An experimental evaluation of the critical potential difference inducing cell membrane electropermeabilization. Biophys J 65:409-413. doi:10.1016/S0006-3495(93) 81052-X

Vasquez JL, Ibsen P, Lindberg H, Gehl J (2015) In vitro and in vivo experiments on electrochemotherapy for bladder cancer. J Urol 193:1009-1015

Wei B, Guo C, Liu S, Sun MZ (2015) Annexin A4 and cancer. Clin Chim Acta 447:72-78. doi:10.1016/j.cca.2015.05.016

Zwaal RF, Comfurius P, Bevers EM (2005) Surface exposure of phosphatidylserine in pathological cells. Cell Mol Life Sci 62:971-988. doi:10.1007/s00018-005-4527-3 